\title{
БОТАНИКА
}

УДК 582.475:581.41:575.222.72

doi: $10.17223 / 19988591 / 38 / 2$

\section{Г.В. Васильева}

Институт мониторинга климатических и экологических систем СО РАН, 2. Томск, Россия

\section{Рост и морфогенез кедра сибирского, кедрового стланика и их гибридов: сравнительный анализ семенного потомства в условиях еx situ}

\author{
Работа выполнена при финансовой поддержке РФФИ, проект № 15-04-03924-а.
}

\begin{abstract}
Проведен сравнительный анализ роста и морфогенеза 7-летнего потомства кедра сибирского (Pinus sibirica), кедрового стланика (P. puтila) и их гибридов в условиях ех situ. Место происхождения семян - смешанная популяция кедра сибирского, кедрового стланика и гибридов, расположенная в дельте Верхней Ангары (Северное Прибайкалье). Наблюдения проведены на семенном потомстве видов игибридов, представленном несколькими семьями полусибсов. Установлено, что среди семенного потомства видов нет особей, которые можно отнести $\kappa$ гибридам первого поколения. В этом возрасте кедр сибирский и кедровый стланик слабо различались, наибольшие отличия наблюдались по числу боковых ветвей и апикальному доминированию. Гибриды превзошли оба родительских вида по высоте дерева и ширине кроны на 10 и 27\%, соответственно, проявив гетерозис. По измеренным морфологическим признакам гибриды оказались ближе к кедровому стланику, чемк кедру сибирскому. Следовательно, их семенное потомство представлено главным образом бэккроссами на кедровый стланик. Слабая дифференциаџия видов и гибридов в молодом возрасте свидетельствует о том, что в полевых условиях их определение затруднительно и необходим сбор растительного материала для дальнейших лабораторных исследований.
\end{abstract}

Ключевые слова: гибридизачия; морфогенез; Pinus sibirica; Pinus pumila; семенное потомство.

\section{Введение}

Кедр сибирский (Pinus sibirica Du Tour) и кедровый стланик (P. pumila (Pall.) Regel) - представители пятихвойных сосен из подрода Strobus, имеющие протяженные ареалы, которые почти полностью находятся на территории России. Ареалы этих видов частично перекрываются в юго-восточной части Восточной Сибири, область перекрывания охватывает Прибайкалье, 
Забайкалье и южную часть Якутии. Во многих растительных сообществах, где кедр сибирский и кедровый стланик произрастают совместно, есть их естественные межвидовые гибриды $[1,2]$. Среди многих примеров гибридизирующих видов хвойных [3] данный случай является редчайшим, так как отличается контрастными жизненными формами родительских видов: кедр сибирский - прямостоячее дерево, кедровый стланик - дерево стелющееся. У сосен есть только еще один похожий пример - гибридизация сосны обыкновенной (P. sylvestris) и сосны горной (P. mugo) [4-6].

Историю исследования гибридизации кедра сибирского и кедрового стланика можно разделить на два этапа, рубежом между которыми служит работа Д.В. Политова с соавт. [7], в которой впервые приведено генетическое доказательство существования генетического обмена между данными видами. Первый этап характеризуется морфологическим описанием предположительно гибридных особей, у которых отмечалась промежуточность разных признаков, относящихся к росту, строению шишки и хвои [8-10]. Второй (современный) этап характеризуется комплексным подходом к изучению процесса и включает морфологический $[1,11]$, физиологический [12] анализ, анализ семенной продуктивности $[2,13]$ и скрещиваемости гибридов [14] с применением генетических [15-17] и молекулярно-генетических методов [18, 19].

В исследованиях естественной гибридизации первоочередной задачей является идентификация гибридов в местах их произрастания. В полевых условиях гибриды кедра сибирского и кедрового стланика достаточно просто определить, используя два признака: габитус и цвет созревающих шишек. Кедр сибирский представляет собой прямостоячее дерево с фиолетовыми шишками, кедровый стланик - стелющееся дерево с зелеными шишками. Типичные гибриды сочетают признаки родительских видов, имея промежуточный габитус и фиолетовые шишки, как у кедра сибирского [1, 20]. Промежуточность габитуса гибридов выражается либо в отсутствии вертикального ствола, который очень часто имеет наклон, либо главный ствол очень короткий с отходящими крупными скелетными ветвями, формирующими чашеобразную крону. Определение молодых неплодоносящих особей весьма затруднительно из-за отсутствия женских шишек и еще не сформировавшейся кроны. Есть еще ряд морфолого-анатомических признаков хвои, которые дифференцируют виды и являются полезными в определении гибридов [16], но их анализ невозможно провести в полевых условиях. А такие признаки, как длина хвои и ее оттенок, слишком изменчивы, чтобы на них полагаться. Таким образом, поиск признаков, с помощью которых можно идентифицировать молодые неплодоносящие особи гибридов, представляет собой актуальную задачу.

Экспедиция в северное Прибайкалье с целью изучения естественной гибридизации кедра сибирского и кедрового стланика проводилась дважды, в 2005 и 2009 гг. В дельте Верхней Ангары, недалеко от пос. Нижнеангарск обнаружена популяция, в которой совместно произрастают виды и гибри- 
ды [21]. В ходе последней экспедиции провели сбор семян для последующего выращивания потомства видов и гибридов в условиях юга Томской области. Такое семенное потомство можно рассматривать как модель, в некоторой степени отражающую естественные процессы в смешанной популяции, состоящей из чистых видов и гибридов. Насколько интенсивно происходит межвидовой генетический обмен в естественной популяции? Есть ли гибриды среди потомства видов? С каким видом проявит большее сходство потомство гибридов? На все эти вопросы можно получить ответы, изучив разнообразие морфологических признаков семенного потомства видов и гибридов из естественной популяции. Ранее для данной популяции установили, что в семенах видов в незначительной степени присутствуют гибридные зародыши, а в семенах гибридов - в основном беккроссы на кедровый стланик [15]. Анализ морфологического разнообразия однолетних сеянцев также выявил предположительно гибридные особи среди семенного потомства видов и показал большое разнообразие в потомстве гибридов [22].

В данной статье представлен следующий этап работы, который рассматривает уже семилетнее потомство видов и гибридов из той же популяции. Таким образом, цель настоящего исследования - выявление морфологических признаков, полезных для идентификации молодых неплодоносящих гибридных особей в полевых условиях, и понимание популяционных процессов в гибридной зоне, направления скрещиваний и морфологических отличий потомства гибридов.

\section{Материалы и методики исследования}

Объект исследования - семенное потомство кедра сибирского, кедрового стланика и их естественных гибридов. Семена собраны в смешанной популяции видов и гибридов, расположенной в дельте р. Верхняя Ангара, около п. Нижнеангарск (Бурятия), 55²7' с. ш., 109³3' в. д., 487 м над ур. м. Посев семян проводили в мае 2010 г. Все семена проходили стратификацию в одинаковых условиях (6 мес при температуре от 0 до $\left.+5^{\circ} \mathrm{C}\right)$. Семенное потомство выращивали в однородных почвенно-климатических условиях на научном стационаре «Кедр» ИМКЭС СО РАН, Томская область $\left(56^{\circ} 13^{\prime}\right.$ с. ш., $84^{\circ} 51^{\prime}$ в. д., 78 м над ур. м.). Посевы обеспечивали минимальным уходом: полив и прополка по мере необходимости. Мероприятий по внесению удобрений, подкормке, защите от болезней, вредителей и заморозков не проводили. Сеянцы видов и гибридов рассаживали в августе 2012 г., расстояние между особями составляло около $20 \mathrm{cм}$. Измерения проводили в сентябре 2016 г., для измерения выбирали деревья с ненарушенной структурой ветвления случайным образом. Всего измерили 276 семилетних деревьев: 7 семей полусибсов кедра сибирского по 10-15 особей в каждой семье, 4 семьи кедрового стланика по 15 особей в каждой семье и 6 семей гибридов по 20 особей в каждой семье. 
Измеряли следующие признаки: высота дерева, ширина кроны, число боковых ветвей первого порядка (ауксибласты и проросшие латентные почки), длина хвои, лидирующей ветви и самой длинной боковой ветви. Расчетные признаки - отношение высоты дерева к ширине кроны, апикальное доминирование, т.е. отношение длины лидирующей ветви к длине боковой. Полученные данные обрабатывали в программе StatSoft STATISTICA 8.0. Сравнение проводили с помощью однофакторного дисперсионного анализа (ANOVA) и теста Ньюмана-Кейсла, анализа главных компонент и корреляций. Нормальность распределения выборок подтверждалась с помощью критерия Колмогорова-Смирнова.

\section{Результаты исследования}

Анализ роста и морфогенеза кедра сибирского, кедрового стланика и их гибридов провели у семилетнего семенного потомства, выращенного в условиях ex situ. Среди семенного потомства видов не выявили ни одной предположительно гибридной особи. Все исследованные особи в потомстве кедра сибирского и кедрового стланика выглядели как типичные представители своего вида. Виды в молодом возрасте слабо различались между собой. У особей кедрового стланика главный ствол, как правило, еще хорошо выражен. Кедровый стланик уступал кедру сибирскому по высоте дерева, длине хвои, числу ветвей и апикальному доминированию (рис. 1). Ширина кроны и ее форма, выраженная как отношение высоты дерева к ширине кроны, у видов статистически одинаковые $(\mathrm{p}<0,05)$. Гибриды в отношении измеренных признаков проявили себя по-разному: ожидаемая морфологическая промежуточность гибридов проявилась только в одном признаке - длине хвои. По высоте дерева и ширине кроны гибриды превзошли оба родительских вида. По сравнению с кедром сибирским, а именно у этого родительского вида наблюдались лучшие показатели роста, превосходство по высоте дерева и ширине кроны составило 10 и 27\% соответственно. Гибриды - более раскидистые, что выразилось в наименьшем показателе формы кроны. По двум оставшимся признакам гибриды оказались неотличимы от родительских видов: по числу ветвей такие же, как кедр сибирский, по апикальному доминированию - как кедровый стланик.

Анализ характера распределения деревьев по числу ветвей показал, что кедр сибирский и гибриды очень похожи, мода и медианы выборок совпадают (рис. 2). Анализ распределения деревьев по значениям апикального доминирования показал, что только у кедрового стланика и гибридов уже есть боковые ветви, равнозначные лидирующей, которые в будущем сформируют стволы-ветви. Более того, у некоторых из них боковая ветвь превзошла лидирующую по длине, что является видоспецифическим признаком для кедрового стланика. У кедра сибирского большинство молодых деревьев $(60,4 \%)$ характеризовались апикальным доминированием в диапазоне 1,61-2,50; 20,8\% 
деревьев имели апикальное доминирование выше 2,50; остальные (18,8\%)меньше 1,60, но никогда не наблюдались значения меньше либо равные 1.
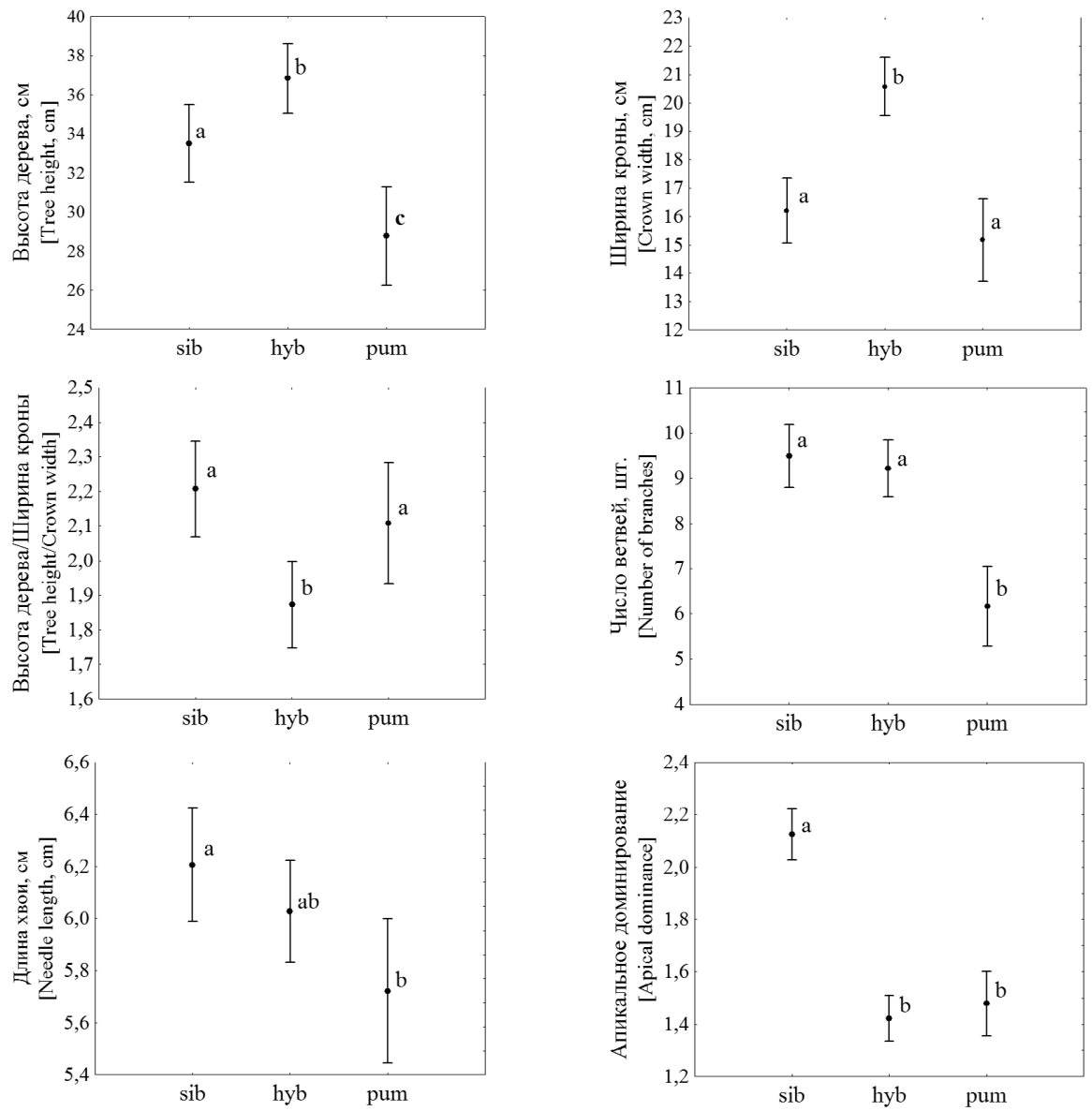

Рис. 1. Сравнение морфологических признаков семилетнего потомства кедра сибирского (sib), кедрового стланика (pum) и их гибридов (hyb) по результатам однофакторного дисперсионного анализа. Точками показаны средние значения, отрезками - 95\%-ные доверительные интервалы.

Разные буквы показывают наличие статистически значимых отличий по тесту Ньюмана-Кейсла, $\mathrm{p}<0,05$; совпадающие буквы указывают на отсутствие отличий

[Fig. 1. Comparison of morphological traits in 7-year seed progeny of Pinus sibirica (sib),

Pinus pumila (pum) and the hybrids (hyb) according to ANOVA. Middle points are means, segments are 0.95 confidence intervals. Letters show differences according to Newman-Keuls test, $p<0.05$ ] 
a
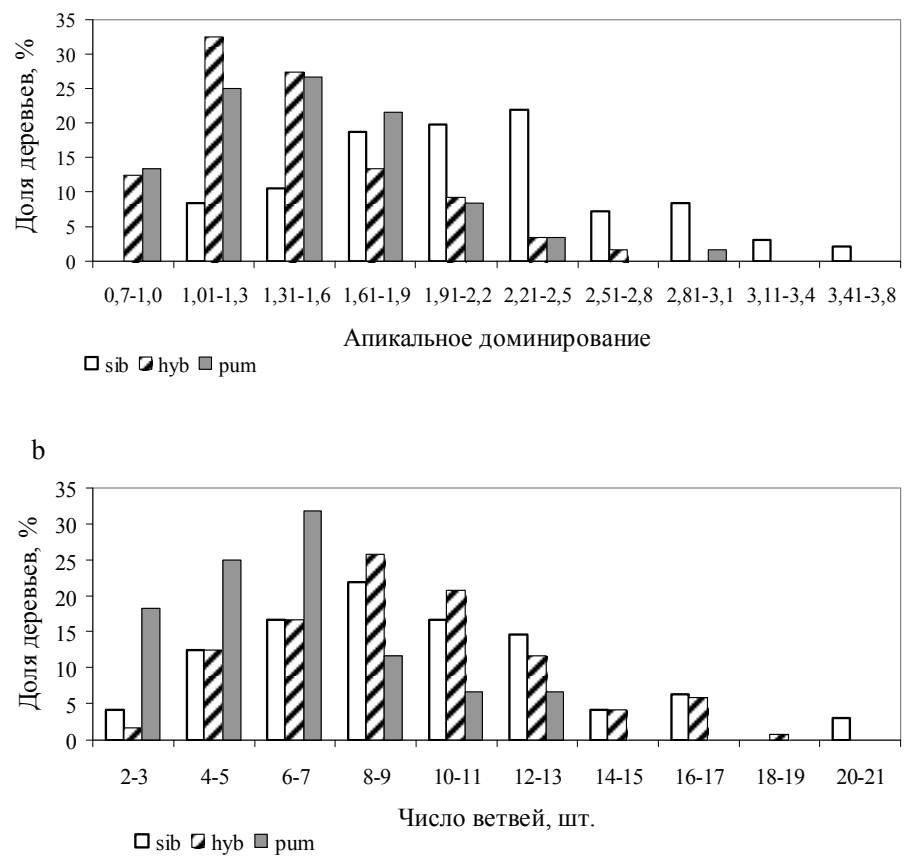

Рис. 2. Распределение деревьев по значениям апикального доминирования $(a)$ и по числу ветвей $(b)$

[Fig. 2. Tree occurrence (\%) of Pinus sibirica (sib), Pinus pumila (pum) and the hybrids (hyb) with different apical dominance values (a) and number of branches (b). On the Y-axis Tree occurrence (\%); on the X-axis - Apical dominance (a) and Number of branches (b)]

Разнообразие семей по измеренным признакам внутри видов и гибридов очень слабое (табл. 1). У кедра сибирского не наблюдалось статистически значимых отличий по половине измеренных признаков, у кедрового стланика - по двум и у гибридов - по одному признаку. Как отмечено выше, гибриды сочетают большое число веток, характерное для кедра сибирского, и низкое апикальное доминирование, характерное для кедрового стланика. Значения этих признаков у исследованных семей видов не перекрывались и характеризовались слабой изменчивостью. Следовательно, эти признаки могут быть полезны для определения гибридов в молодом возрасте.

Анализ главных компонент подтвердил слабую дифференциацию видов между собой и гибридов от видов (см. рис. 3). Первые два фактора объясняют большую часть $(81,7 \%)$ изменчивости. Наибольшая корреляция фактора 1 наблюдалась с высотой дерева $(\mathrm{r}=0,94)$ и числом ветвей $(\mathrm{r}=0,80)$. Это те признаки, высокие значения которых характеризуют кедр сибирский. Фактор 2 в большей степени коррелировал с апикальным доминированием $(\mathrm{r}=0,95)$ и шириной кроны $(\mathrm{r}=-0,65)$. Низкие значения апикального доми- 
рина кроны у видов связана с числом ветвей, у кедрового стланика еще и с апикальным доминированием.

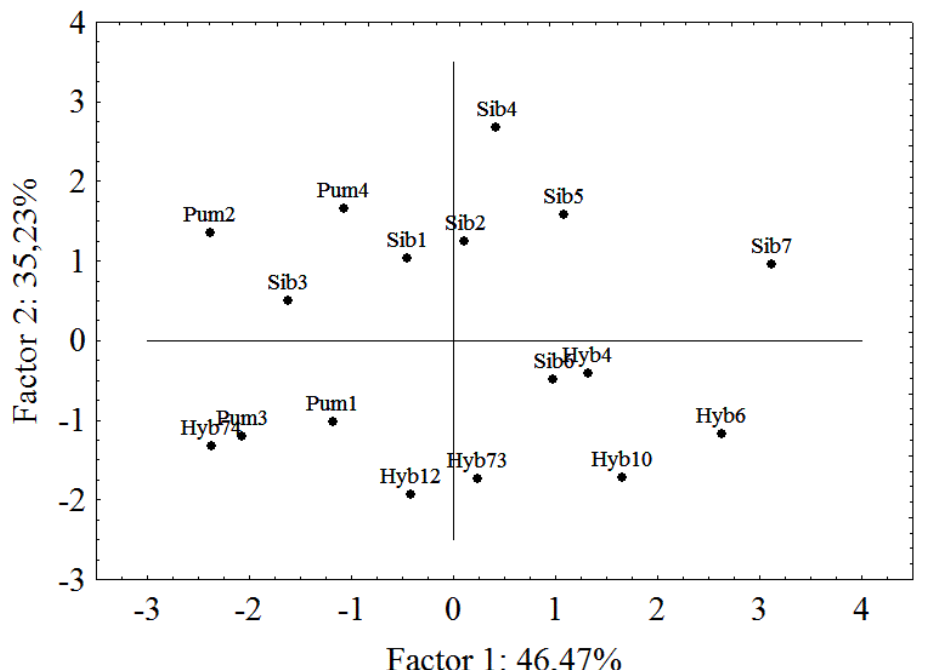

Рис. 3. Распределение семей кедра сибирского (sib), кедрового стланика (pum) и гибридов (hyb) в плоскости главных компонент

[Fig. 3. Scatter plot of half-sibs of Pinus sibirica (sib), Pinus pumila (pum) and the hybrids (hyb) in the first two factors calculated with principal component analysis]

Т а б л и ц а 2 [Table 2]

Корреляция измеренных признаков у кедра сибирского (sib), кедрового стланика (pum) и гибридов (hyb)

[Correlations of measured traits in Pinus sibirica (sib), Pinus pumila (pum) and the hybrids (hyb)]

\begin{tabular}{|l|c|c|c|c|c|c|}
\hline \multirow{2}{*}{\begin{tabular}{c} 
Признак \\
\multicolumn{1}{|c|}{$[$ Trait] }
\end{tabular}} & \multicolumn{3}{|c|}{$\begin{array}{c}\text { Высота дерева } \\
\text { Tree height] }\end{array}$} & \multicolumn{3}{c|}{ Ширина кроны } \\
\cline { 2 - 8 } & $\begin{array}{c}\text { Sib } \\
\mathrm{N}=96\end{array}$ & $\begin{array}{c}\text { Pum } \\
\mathrm{N}=60\end{array}$ & $\begin{array}{c}\text { Hyb } \\
\mathrm{N}=120\end{array}$ & $\begin{array}{c}\text { Sib } \\
\mathrm{N}=96\end{array}$ & $\begin{array}{c}\text { Pum } \\
\mathrm{N}=60\end{array}$ & $\begin{array}{c}\text { Hyb } \\
\mathrm{N}=120\end{array}$ \\
\hline Ширина кроны [Crown width] & $\mathbf{0 , 7 1 4}$ & 0,235 & $\mathbf{0 , 5 6 5}$ & - & - & - \\
\hline $\begin{array}{l}\text { Число ветвей } \\
\text { [Number of branches] }\end{array}$ & $\mathbf{0 , 4 8 8}$ & 0,023 & $\mathbf{0 , 3 0 4}$ & $\mathbf{0 , 5 2 0}$ & $\mathbf{0 , 3 6 0}$ & $\mathbf{0 , 2 5 5}$ \\
\hline Длина хвои [Needle length] & $\mathbf{0 , 3 3 2}$ & 0,158 & $\mathbf{0 , 3 4 8}$ & 0,207 & $-0,199$ & $\mathbf{0 , 3 4 6}$ \\
\hline $\begin{array}{l}\text { Апикальное доминирование } \\
\text { [Арiсаl dominance] }\end{array}$ & 0,230 & 0,152 & $\mathbf{0 , 2 8 6}$ & $-0,202$ & $\mathbf{- 0 , 3 7 8}$ & $-0,012$ \\
\hline
\end{tabular}

Примечание. Статистически значимые корреляции $(\mathrm{p}<0,01)$ выделены жирным курсивом. [Note. Correlations with high significance level $(\mathrm{p}<0.01)$ are in bold italics].

В целом у гибридов наблюдалась достаточно тесная взаимосвязь ростовых признаков, что отличало их от кедрового стланика. От обоих родительских видов гибриды отличались положительной корреляцией высоты дерева и апикального доминирования, а также ширины кроны и длины хвои. Однако, как показано выше, семьи гибридов разные, и корреляции признаков 
внутри семьи могут существенно отличаться от общей полученной тенденции взаимосвязи признаков.

\section{Обсуждение результатов исследования}

В естественной популяции в дельте Верхней Ангары, где совместно произрастают виды и гибриды, доминирует кедровый стланик, на один плодоносящий гибрид приходится 3 плодоносящих кедра и 60 стлаников [2]. Семенная продуктивность гибридов из данной популяции достаточно хорошая: до четверти семяпочек давали полноценные семена [22]. Для смешанной популяции видов и гибридов из дельты Верхней Ангары установлено, что в семенах гибридов большинство зародышей $(75,49 \%)$ - результат опыления пыльцой кедрового стланика, и лишь небольшая часть образовалась от опыления пыльцой кедра сибирского и других гибридных особей: 12,75 и $11,76 \%$ соответственно [15]. Учитывая, что гибриды успешно скрещиваются с родительскими видами в обоих направлениях: могут выступать и в качестве материнского растения и как доноры пыльцы [14], а фенология развития их женских шишек близка к таковой у кедрового стланика [23], это ожидаемый результат. Поскольку в гибридной зоне при прочих равных условиях опыление происходит пыльцой того вида, который доминирует в насаждении $[24,25]$, в данном случае это кедровый стланик.

Анализ разнообразия этого же семенного потомства видов и гибридов в однолетнем возрасте показал, что среди семенного потомства видов есть небольшая доля сеянцев с нетипичной морфологией, сближающей ее с другим видом, которые, как предполагалось, могли представлять F1 [22]. В семилетнем возрасте среди семенного потомства видов не обнаружили ни одной особи с нехарактерной морфологией, которая имела бы предположительно гибридную природу. Вероятно, нетипичная морфология однолетних сеянцев кедра сибирского и кедрового стланика отражала только их внутривидовое разнообразие. В этой же работе показано, что семенное потомство гибридов, имея большой разброс значений морфологических признаков, все же ближе к кедровому стланику. Среди семилетнего семенного потомства гибридов характер разнообразия морфологических признаков сохранился, следовательно, опыление в природной смешанной популяции в дельте Верхней Ангары действительно происходит пыльцой кедрового стланика, доминирующего вида. Однако для окончательного подтверждения этого вывода требуется молекулярно-генетический анализ.

Разница в дифференциации однолетнего и семилетнего семенного потомства видов и гибридов связана с этапностью онтогенеза. Известно, что рост у сеянцев, молодых и взрослых деревьев сосен слабо связан между собой $[26,27]$. Генетический контроль роста меняется в зависимости от возраста, что показано как изменение экспрессии генов на некоторых видах хвойных [28, 29]. 
У семилетнего потомства гибридов наблюдалось превосходство над родительскими видами по высоте дерева и ширине кроны. Известно, что гетерозис у сосен - вполне обычное явление [30, 31], оно широко используется в плантационном лесовыращивании [32, 33]. Однако с возрастом его эффект нивелируется, например, гибриды $P$. contorta и $P$. banksiana сохраняют гетерозис до 14 лет [34]. Скорее всего, такой же сценарий развития ждет исследованные гибриды, тем более что родительские виды имеют огромные различия в размерах и форме кроны. Тем не менее даже небольшое преимущество в росте у гибридов по сравнению с родительскими видами в молодом возрасте может обеспечить им определенные преимущества в естественных условиях и способствовать успешной конкурентной борьбе с родительскими видами.

Рост кедра сибирского и кедрового стланика начинается одинаково, проростки морфологически слабо различаются, и не только у этих видов, но и у других сосен. Однолетние сеянцы видов достаточно хорошо дифференцированы и отличаются типами развития, у кедрового стланика ювенильный этап обычно продолжается 2 года, у кедра сибирского - 1 год [35]. Одно- и двухлетние сеянцы кедрового стланика могут превосходить сеянцы кедра сибирского по высоте из-за более длинного ювенильного побега. С годами интенсивность роста видов возрастает, однако закономерности роста у них совершенно разные, и в зрелом возрасте они существенно различаются не просто морфологическими особенностями побегов и хвои, а жизненной формой. Эти закономерности проявились в разных корреляциях простых морфогенетических признаков у молодых деревьев. Очевидно, первостепенное значение для формирования кроны имеет апикальное доминирование как контроль, определяемый апексом лидирующего побега над ростом боковых почек $[36,37]$. Этот контроль в конечном счете определяет жизненную форму вертикального дерева, коим является кедр сибирский. В молодом возрасте кедр сибирский характеризуется одним стволом, ветви первого порядка, которые регулярно закладываются с 4-5 лет, сильно уступают ему в росте и однородны по размеру.

С первых лет жизни развитие кедрового стланика идет по моноподиальному типу, но, в отличие от прямостоячих видов хвойных, его боковые ветви выходят из-под апикального контроля на ранних этапах онтогенеза, что приводит практически к одинаковому росту ранее лидировавшей и боковых ветвей [38]. Уже в молодом возрасте кедровый стланик имеет несколько единообразных стволов-ветвей, формирующих чашеобразную крону, число которых с возрастом увеличивается [2]. Наблюдения в условиях ex situ показали, что стланик может сохранять вертикальный ствол и моноподиальный тип ветвления до 7 и даже до 11 лет. При этом в приземной части стволика, как правило, имеется характерный саблевидный изгиб.

Гибриды, описанные в природе, характеризуются промежуточным габитусом, который складывается в результате избирательного апикального до- 
минирования [21]. Избирательность доминирования приводит к тому, что взрослые особи гибридов с выраженным стволом имеют сильно раскидистую крону, части которой могут легко ломаться зимой под воздействием навала снега. Гибриды как бэккроссы на кедровый стланик проявят с ним большее сходство, чем с кедром сибирским. Сформируют ли такие гибриды жизненную форму стелющегося дерева, остается пока открытым вопросом. Кедровый стланик может иметь одноствольную прямостоячую форму, особи с такой формой роста описаны в области симпатрии с кедром сибирским и являются следствием гибридизации $[8,10,39]$. Возможно, одноствольный прямостоячий кедровый стланик существует за пределами гибридной зоны. Однако известно только одно упоминание об этом [40], по-видимому, формирование прямостоячего габитуса у данного вида крайне редкое явление. К тому же неясно, как проявит себя генетическая составляющая, унаследованная от кедра сибирского, и позволит ли реализовать гибридной особи жизненную форму, присущую кедровому стланику.

\section{Заключение}

Потомство кедра сибирского, кедрового стланика и их гибридов в семилетнем возрасте слабо различается по морфологическим признакам. Поэтому в полевых условиях, особенно в смешанных популяциях, следует обращать внимание на крону дерева в целом, выделяя особи, отклоняющиеся от среднестатистического представителя своего вида. Более надежную идентификацию молодых деревьев гибридов можно провести только в лабораторных условиях, используя более тонкие методы исследования структурных признаков хвои и молекулярно-генетических маркеров. Исследованное потомство гибридов в основном представлено бэккроссами на кедровый стланик, это говорит о том, что в Северном Прибайкалье гибридизация приобретает вид интрогрессии, идущей от кедрового стланика к кедру сибирскому.

\section{Лuтература}

1. Горошкевич С.Н. О возможности естественной гибридизации Pinus sibirica и Pinus pumila (Pinaceae) в Прибайкалье // Ботанический журнал. 1999. Т. 84, № 9. С. 48-57.

2. Горошкевич С.Н., Васильева Г.В., Попов А.Г. О гибридизации кедра сибирского и кедрового стланика в западной части Станового нагорья // Лесное хозяйство. 2008. № 6. С. 25-27.

3. Коропачинский И.Ю., Милютин Л.И. Естественная гибридизация древесных растений. Новосибирск : Гео, 2006. 223 с.

4. Kormutak A., Demankova B., Gömöry D. Spontaneous Hybridization between Pinus sylvestris L. and P. mugo Turra in Slovakia // Silvae Genetica. 2008. Vol. 57, № 2. PP. 76-82.

5. Wachowiak W., Stephan B.R., Schulze I., Prus-Głowacki W., Ziegenhagen B. A critical evaluation of reproductive barriers between closely related species using DNA markers a case study in Pinus // Plant Systematics and Evolution. 2006. Vol. 257. PP. 1-8. 
6. Wachowiak W., Lewandowski A., Prus-Głowacki W. Reciprocal controlled crosses between Pinus sylvestris and P. mugo verified by a species-specific cpDNA marker// Journal of Applied Genetics. 2005. Vol. 46 (1). PP. 41-43.

7. Politov D.V., Belokon M.M., Maluchenko O.P., Belokon Y.S., Molozhnikov V.N., Mejnartowicz L.E., Krutovsky K.V. Genetic evidence of natural hybridization between Pinus sibirica Du Tour and P. pumila (Pall.) Regel. // Forest Genetics. 1999. Vol. 6, № 1. PP. 41-48.

8. Поздняков Л.К. Древовидная форма кедрового стланца // Ботанический журнал. 1952. Т. 37, № 5. С. 688-691.

9. Галазий Г.И. Вертикальный предел древесной растительности в горах Восточной Сибири и его динамика // Труды Ботанического института им. В.Л. Комарова АН СССР. Сер. 3 (Геоботаника). 1954. Вып. 9. С. 210-329.

10. Моложников В.Н. Кедровый стланик горных ландшафтов Северного Прибайкалья. М. : Наука, 1975. 203 с.

11. Goroshkevich S.N., Popov A.G., Vasilieva G.V. Ecological and morphological studies in the hybrid zone between Pinus sibirica and Pinus pumila // Annals of Forest Research. 2008. Vol. 51. PP. 43-52.

12. Зотикова А.П., Васильева Г.В., Бендер О.Г. Фотосинтетические и дыхательные процессы в хвое кедра сибирского, кедрового стланика и гибридов между ними // Вестник Томского государственного университета. Биология. 2014. № 389. С. 268-274.

13. Васильева Г.В. Семенная продуктивность гибридов кедра сибирского и кедрового стланика на северном макросклоне хребта Хамар-Дабан // Вестник Московского государственного университета леса - Лесной вестник. 2014. № 1 (100). С. 85-89.

14. Vasilyeva G.V., Goroshkevich S.N. Crossability of Pinus sibirica and P. pumila with their hybrids // Silvae Genetica. 2013. Vol. 62, № 1-2. PP. 61-68.

15. Петрова Е.А., Горошкевич С.Н., Политов Д.В., Белоконь М.М., Попов А.Г., Васильева Г.В. Семенная продуктивность и генетическая структура популяций в зоне естественной гибридизации кедра сибирского и кедрового стланика // Хвойные бореальной зоны. 2007. Т. 24, № 2-3. С. 331-335.

16. Петрова Е.А., Бендер О.Г., Горошкевич С.Н., Белоконь Ю.С., Белоконь М.М., Политов Д.В. Аллозимная изменчивость и структура хвои естественных гибридов кедра сибирского и кедрового стланика // Хвойные бореальной зоны. 2010. Т. 27, № 1-2. C. 154-159.

17. Петрова Е.А., Горошкевич С.Н., Белоконь М.М., Белоконь Ю.С., Политов Д.В. Естественная гибридизация кедра сибирского (Pinus sibirica Du Tour) и кедрового стланика (P. pumila (Pall.) Regel) в Южном Забайкалье // Хвойные бореальной зоны. 2012. T. 30, № 1-2. C. 152-156.

18. Vasilyeva G.V., Semerikov V.L. Application of amplified fragment length polymorphisms markers to study the hybridization between Pinus sibirica and P. pumila // Annals of Forest Research. 2014. Vol. 57 (2). PP. 175-180. doi: 10.15287/afr.2014.219

19. Мглинец А.В., Соколов В.А., Петрова Е.А., Горошкевич С.Н. Сравнительное изучение первичной структуры фрагмента гена LEA у Pinus sibirica Du Tour и Pinus pumila (Pallas) Regel // Генетика. 2014. T. 50, № 2. C. 167-171.

20. Goroshkevich S.N. Natural hybridization between Russian stone pine (Pinus sibirica) and Japanese stone pine (Pinus pumila) // Breeding and genetic resources of five-needle pines: growth, adaptability, and pest resistance: proceedings of the IUFRO Five-Needle Pines Working Party Conference, July 23-27, 2001, Medford, Oregon, USA. Fort Collins, CO : U.S. Department of Agriculture, Forest Service, Rocky Mountain Research Station, 2004. PP. 169-171.

21. Goroshkevich S.N., Popov A.G., Vasilieva G.V. Ecological and morphological studies in the hybrid zone between Pinus sibirica and Pinus pumila // Annals of Forest Research. 2008. Vol. 51. PP. 43-52. 
22. Васильева Г.В., Горошкевич С.Н. Семеношение и рост потомства гибридов между кедром сибирским и кедровым стлаником в сравнении с родительскими видами // Хвойные бореальной зоны. 2012. Т. 30, № 1-2. С. 28-32.

23. Васильева Г.В., Жук Е.А., Попов А.Г. Фенология цветения кедра сибирского, кедрового стланика и гибридов между ними // Вестник Томского государственного университета. Биология. 2010. № 1 (9). С. 61-67.

24. Burgess K.S., Morgan M., Deverno L., Husband B.C. Asymmetrical introgression between two Morus species (M. alba, M. rubra) that differ in abundance // Molecular Ecology. 2005. Vol. 14. PP. 3471-3483.

25. Lepais O., Petit R.J., Guichoux E., Lavabre J.E., Alberto F., Kremer A., Gerber S. Species relative abundance and direction of introgression in oaks // Molecular Ecology. 2009. Vol. 18 (10). PP. 2228-2242.

26. Greenwood M.S. Juvenility and maturation in conifers: current concepts // Tree Physiology. 1995. Vol. 15. PP. 433-438.

27. Nelson C.D., Weng C., Kubisiak T.L., Stine M., Brown C.L. On the number of genes controlling the grass stage in longleaf pine // Journal of Heredity. 2003. Vol. 94 (5). PP. 392-398.

28. Alvarez C., Valledor L., Hasbún R., Sanchez-Olate M., Ríos D. Variation in gene expression profile with aging of Pinus radiate D. Don // BMC Proceedings 2011. Vol. 5 (Suppl 7). PP. 62.

29. Li W., Han S., Qi L., Zhang Sh. Transcriptome resources and genome-wide marker development for Japanese larch (Larix kaempferi) // Frontiers of Agricultural Science and Engineering. 2014. Vol. 1 (1). PP. 77-84.

30. Mirov N.T. The genus Pinus. New York : Ronald, 1967. 602 p.

31. Gwaze D.P. Performance of some interspecific F1 pine hybrids in Zimbabwe // Forest Genetics. 1999. Vol. 6 (4). PP. 283-289.

32. Nikles D.G. Experience with some Pinus hybrids in Queensland, Australia // Hybrid breeding and genetics of forest trees: proceedings of QFRI/CRC-SRF Symposium, 9-14 April, 2000, Noosa, Quinsland, Australia. PP. 27-43.

33. Dungey H.S. Pine hybrids - a review of their use performance and genetics // Forest ecology and management. 2001. Vol. 148. PP. 243-258.

34. Duffield J.W., Snyder E.B. Benefits from hybridizing American forest tree species // Journal of forestry. 1958. Vol. 56 (11). PP. 809-815.

35. Горошкевич С.Н., Попов А.Г. Морфоструктура и развитие побегов у 5-хвойных сосен Северной и Восточной Азии: филогенетическая и климатическая интерпретация // Журнал Сибирского федерального университета. Биология. 2009. № 2 (1). С. 54-79.

36. Минина Е.Г., Третьякова И.Н. Геотропизм и пол у хвойных. Новосибирск : Наука, 1983. $200 \mathrm{c}$.

37. Cline M.G. Concepts and terminology of apical dominance // American Journal of Botany. 1997. Vol. 84 (9). PP. 1064-1069.

38. Хоментовский П.А. Экология кедрового стланика Pinus pumila (Pallas) Regel на Камчатке: (общий обзор). Владивосток : Дальнаука, 1995. 227 с.

39. Бобринев В.П., Пак Л.Н. Кедровый стланик (Pinus pumila) древовидной формы на севере Забайкальского края // Международный журнал научных и прикладных исследований. 2014. № 8. С. 9-13.

40. Грибков П.Ф. Кедровый стланик древовидной формы на Камчатке // Вопросы географии Камчатки. 1964. № 2. С. 114-115.

Поступила в редакиию 09.02.2017 г.; повторно 20.04.2017 г.; принята 03.05.2017 г.; опубликована 15.06.2017 г. 
Васильева Галина Валериевна - канд. биол. наук, н.с. лаборатории дендроэкологии Института мониторинга климатических и экологических систем СО РАН (Россия, 634055, г. Томск, пр. Академический, 10/3).

E-mail: galina_biology@mail.ru

Vasilyeva GV. Growth and morphogenesis of Siberian stone pine, Siberian dwarf pine and their hybrids: comparative analysis of seed progeny ex situ. Vestnik Tomskogo gosudarstvennogo universiteta. BiologiyaTomsk State University Journal of Biology. 2017;38:28-44. doi: 10.17223/19988591/38/2 In Russian, English summary

\section{Galina V. Vasilyeva}

Institute of Monitoring of Climatic and Ecological Systems, Siberian Branch of the Russian Academy of Sciences, Tomsk, Russian Federation

\section{Growth and morphogenesis of Siberian stone pine, Siberian dwarf pine and their hybrids: comparative analysis of seed progeny ex situ}

Pinus sibirica and P. pumila have vast geographic distributions; their overlapping range spreads in the Pribaikalia, Zabaikalia and the southern part of Yakutia. There are natural interspecies hybrids in many plant communities where the species grow together. Mixed population with $P$. sibirca, $P$. pumila and their hybrids was found in the Upper Angara River delta $\left(55^{\circ} 47^{\prime} \mathrm{N}, 109^{\circ} 33^{\prime} \mathrm{E}, 487 \mathrm{~m}\right.$ a.s.1.). We collected seeds from the hybrids and the species in this population and then sowed them at the Kedr field station managed by the Institute of Monitoring of Climatic and Ecological Systems SB RAS (Tomsk oblast, $56^{\circ} 13^{\prime} \mathrm{N}, 84^{\circ} 51^{\prime} \mathrm{E}, 78 \mathrm{~m}$ a.s.l.). The aim of the research was detection of morphological traits useful for identification of young not cone-bearing hybrid trees in the field, and understanding of the population processes in the hybrid zone, tree cross directions and morphological differences of hybrid seed progeny. The objects of the study were 7-year seed progeny of the species ( 7 half-sib families in $P$. sibirica and 4 half-sibs in P. pumila) and the hybrids (6 half-sib families). In total, we measured 276 trees. We measured tree height, crown width, number of lateral branches (long shoots and grown latent buds), needle length, length of the longest terminal shoot, and length of the longest lateral shoot. We calculated crown shape (tree height / crown width) and apical dominance (ratio of length of the longest terminal shoot to length of the longest lateral shoot).

Seed progeny of the species was usual, putative hybrids were not found among them. Although adult trees of the species have a number of differences, young trees are similar in many ways. P. pumila was characterized by decreased tree height, needle length, number of branches and apical dominance, compared to P. sibirica (See Figure 1). The species did not have statistically significant differences in crown width and crown shape. Hybrids exceeded both species in tree height and crown width. In comparison with P. sibirica, characterized by the best growth parameters, hybrid superiority was $10 \%$ and $27 \%$, respectively. The number of branches and apical dominance differentiated the species the most (See Fig. 2). Half-sib variability among both the species and the hybrids was weak (See Table 1). Principal component analysis showed poor differentiation between the species and between the species and the hybrids (See Figure 3). Seed progeny of the hybrids was closer to P. pumila according to the measured traits. Although adult trees of the species have contrast morphology and different life-forms, young trees of the species are morphologically similar. Correlation analysis revealed principal differences between the species (See Table 2). P. sibirica was characterized by strong relation between tree height and other growth traits; on the contrary, there are no traits correlated with tree height in P. pumila. 
Thus, the studied hybrid seed progeny are mainly backcrosses to P. pumila. It means that in the natural population in the Upper Angara River delta pollination occurs by the prevailing species, . pumila. Since hybrid seed progeny does not differ much from the species, its identification is difficult in the field and requires plant material for further study in the laboratory.

The article contains 3 Figures, 2 Tables, 40 References.

Key words: hybridization; morphogenesis; Pinus sibirica; Pinus pumila; seed progeny.

Funding: This work was partially supported by the Russian Foundation for Basic Research (Project No 15-04-03924-a).

\section{References}

1. Goroshkevich SN. O vozmozhnosti estestvennoy gibridizatsii Pinus sibirica i Pinus pumila (Pinaceae) v Pribaykal'e [On the possibility of natural hybridization Pinus sibirica and Pinus pumila (Pinaceae) in the Baikal region]. Botanicheskiy zhurnal - Botanical Journal. 1999;84(9):48-57. In Russian

2. Goroshkevich SN, Vasilyeva GV, Popov AG. O gibridizatsii kedra sibirskogo i kedrovogo stlanika v zapadnoy chasti Stanovogo nagor'ya [On the hybridization of Siberian stone pine and Siberian dwarf pine in the western part of the Stanovoe Upland]. Lesnoe khozyaystvo. 2008;6:25-27. In Russian

3. Koropachinskiy IYu, Milyutin LI. Natural hybridization of woody plants. Novosibirsk: Publ. Geo; 2006. 223 p. In Russian

4. Kormutak A, Demankova B, Gömöry D. Spontaneous Hybridization between Pinus sylvestris L. and P. mugo Turra in Slovakia. Silvae Genetica. 2008;57(2):76-82.

5. Wachowiak W, Stephan BR, Schulze I, Prus-Głowacki W, Ziegenhagen B. A critical evaluation of reproductive barriers between closely related species using DNA markers - a case study in Pinus. Pl. Syst. Evol. 2006;257:1-8. doi: 10.1007/s00606-005-0363-z

6. Wachowiak W, Lewandowski A, Prus-Głowacki W. Reciprocal controlled crosses between Pinus sylvestris and P. mugo verified by a species-specific cpDNA marker. J Appl Genet. 2005;46(1):41-43. PMID: 15741663

7. Politov DV, Belokon MM, Maluchenko OP, Belokon YS, Molozhnikov VN, Mejnartowicz LE, Krutovsky KV. Genetic evidence of natural hybridization between Pinus sibirica Du Tour and P. pumila (Pall.) Regel. Forest Genetics. 1999;6(1):41-48.

8. Pozdnyakov LK. Drevovidnaya forma kedrovogo stlantsa [Tree-like form of Siberian dwarf pine]. Botanicheskiy zhurnal - Botanical Journal. 1952;37(5):688-691. In Russian

9. Galaziy GI. Vertikal'nyy predel drevesnoy rastitel'nosti v gorakh Vostochnoy Sibiri i ego dinamika [The vertical limit of tree vegetation in the mountains of Eastern Siberia and its dynamics]. Trudy Botanicheskogo instituta im. VL Komarova AN SSSR [Proceedings of VL Komarov Botanical Institute AS of the USSR]. 1954;3(2):210-329. In Russian

10. Molozhnikov VN. Kedrovyy stlanik gornykh landshaftov Severnogo Pribaykal'ya [Siberian dwarf pine in mountain landscapes in the northern Baikal region]. Moscow: Nauka Publ.; 1975. 203 p. In Russian

11. Goroshkevich SN, Popov AG, Vasilieva GV. Ecological and morphological studies in the hybrid zone between Pinus sibirica and Pinus pumila. Annals of Forest Research. 2008;51:43-52.

12. Zotikova AP, Vasilyeva GV, Bender OG. Photosynthetic and respiratory processes in the needle of the Siberian stone pine, the Siberian dwarf pine and their hybrids. Vestnik Tomskogo gosudarstvennogo universiteta - Tomsk State University Journal. 2014;389:268274. In Russian, English summary

13. Vasilyeva GV. Seed efficiency of hybrids between Siberian stone pine and Siberian dwarf pine from northern slope of Khamar-Daban ridge. Vestnik MGUL-Lesnoy vestnik-Forestry Bulletin. 2014;1(100):85-89. In Russian 
14. Vasilyeva GV, Goroshkevich SN. Crossability of Pinus sibirica and P. pumila with their hybrids. Silvae Genetica. 2013;62(1-2):61-68.

15. Petrova EA, Goroshkevich SN, Politov DV, Belokon MM, Popov AG, Vasilyeva GV. Semennaya produktivnost' i geneticheskaya struktura populyatsiy $\mathrm{v}$ zone estestvennoy gibridizatsii kedra sibirskogo i kedrovogo stlanika [Seed productivity and genetic structure of populations in the natural hybrid zone of Siberian stone pine and Siberian dwarf pine]. Khvoynye boreal'noy zony. 2007;24(2-3):331-335. In Russian

16. Petrova EA, Bender OG, Goroshkevich SN, Belokon YS, Belokon MM, Politov DV. Allozyme variation and needle structure of natural hybrids between Siberian Stone pine and Siberian Dwarf pine. Khvoynye boreal'noy zony. 2010;27(1-2):154-159. In Russian

17. Petrova EA, Goroshkevich SN, Belokon MM, Belokon YS, Politov DV. Estestvennaya gibridizatsiya kedra sibirskogo (Pinus sibirica Du Tour) i kedrovogo stlanika (P. pumila (Pall.) Regel) v Yuzhnom Zabaykal'e [Natural hybridization of Siberian stone pine (Pinus sibirica Du Tour) and Siberian dwarf pine (P. pumila (Pall.) Regel) in the southern Transbaikalia]. Khvoynye boreal'noy zony. 2012;30(1-2):152-156. In Russian

18. Vasilyeva GV, Semerikov VL. Application of amplified fragment length polymorphisms markers to study the hybridization between Pinus sibirica and P. pumila. Annals of Forest Research. 2014;57(2):175-180. doi: 10.15287/afr.2014.219

19. Mglinets AV, Sokolov VA, Petrova EA, Goroshkevich SN. Comparative sequence analysis of the LEA gene fragment in Pinus sibirica Du Tour and Pinus pumila (Pallas) Regel. Russ J Genet. 2014;50:149-152. doi: 10.7868/S0016675814020088

20. Goroshkevich SN. Natural hybridization between Russian stone pine (Pinus sibirica) and Japanese stone pine (Pinus pumila). In: "Breeding and genetic resources of five-needle pines: Growth, adaptability, and pest resistance” 2001 July 23-27; Medford, OR, USA. IUFRO Working Party 2.02.15. Proceedings RMRS-P-32. Sniezko RA, Samman S, Schlarbaum SE and Kriebel HB, editors. Fort Collins, CO: U.S. Department of Agriculture, Forest Service, Rocky Mountain Research Station; 2004. pp. 169-171.

21. Goroshkevich SN, Popov AG, Vasilieva GV. Ecological and morphological studies in the hybrid zone between Pinus sibirica and Pinus pumila. Annals of Forest Research. 2008;51:43-52.

22. Vasilyeva GV, Goroshkevich SN. Semenoshenie i rost potomstva gibridov mezhdu kedrom sibirskim i kedrovym stlanikom v sravnenii s roditel'skimi vidami [Seed production and growth of the progeny of hybrids between Siberian stone pine and Siberian dwarf pine in comparison with parental species]. Khvoynye boreal'noy zony. 2012;30(1-2):28-32. In Russian

23. Vasilyeva GV, Zhuk EA, Popov AG. Flowering phenology of the Siberian stone pine (Pinus sibirica Du Tour), Japanese stone pine (Pinus pumila (Pall.) Regel.) and their hybrids. Vestnik Tomskogo gosudarstvennogo universiteta. Biologiya - Tomsk State University Journal of Biology. 2010;1(9):61-67. In Russian, English summary

24. Burgess KS, Morgan M, Deverno L, Husband BC. Asymmetrical introgression between two Morus species (M. alba, M. rubra) that differ in abundance. Molecular Ecology. 2005;14:3471-3483. doi: 10.1111/j.1365-294X.2005.02670.x

25. Lepais O, Petit RJ, Guichoux E, Lavabre JE, Alberto F, Kremer A, Gerber S. Species relative abundance and direction of introgression in oaks. Molecular Ecology. 2009;18(10):22282242. doi: 10.1111/j.1365-294X.2009.04137.x

26. Greenwood MS. Juvenility and maturation in conifers: current concepts. Tree Physiology. 1995;15(7-8):433-438. doi: 10.1093/treephys/15.7-8.433

27. Nelson CD, Weng C, Kubisiak TL, Stine M, Brown CL. On the number of genes controlling the grass stage in longleaf pine. Journal of Heredity. 2003;94(5):392-398. doi: 10.1093/ jhered/esg086

28. Alvarez C, Valledor L, Hasbún R, Sanchez-Olate M, Ríos D. Variation in gene expression profile with aging of Pinus radiate D. Don. BMC Proceedings. 2011;5(Suppl 7):62. doi: 10.1186/1753-6561-5-S7-P62 
29. Li W, Han S, Qi L, Zhang Sh. Transcriptome resources and genome-wide marker development for Japanese larch (Larix kaempferi). Front. Agr. Sci. Eng. 2014;1(1):77-84. doi: 10.15302/J-FASE-2014010

30. Mirov NT. The genus Pinus. New York: Ronald Publ.; 1967. 602 p.

31. Gwaze DP. Performance of some interspecific F1 pine hybrids in Zimbabwe. Forest Genetics. 1999;6(4):283-289.

32. Nikles DG. Experience with some Pinus hybrids in Queensland, Australia. In: "Hybrid Breeding and Genetics of Forest Trees". Proceedings of QFRI/CRC-SPF Symposium (914 April 2000, Noosa, Queensland, Australia). Compiled by Dungey HS, Dieters MJ and Nikles DG. Department of Primary Industries, Brisbane; 2000. pp. 27-43.

33. Dungey HS. Pine hybrids - a review of their use performance and genetics. Forest Ecology and Management. 2001;148:243-258.

34. Duffield JW, Snyder EB. Benefits from hybridizing American forest tree species. Journal of Forestry. 1958;56(11):809-815.

35. Goroshkevich SN, Popov AG. Shoot morphological structure and development in 5-needle pines of northern and eastern Asia: Phylogenetic and climatic interpretation. Zhurnal Sibirskogo federal'nogo universiteta. Biologiya - Journal of Siberian Federal University. Biology. 2009;2(1):54-79. In Russian, English summary

36. Minina EG, Tret'yakova IN. Geotropizm i pol u khvoynykh [Geotropism and sex in conifers]. Novosibirsk: Nauka, Siberian Branch Publ.; 1983. 200 p. In Russian

37. Cline MG. Concepts and terminology of apical dominance. American Journal of Botany. 1997;84(9):1064-1069. PMID: 21708661

38. Khomentovsky PA. Ecology of Siberian dwarf pine (Pinus pumila (Pallas) Regel) in Kamchatka (General survey). Vladivistok: Dalnauka Publ.; 1995. 227 p. In Russian

39. Bobrinev VP, Pak LN. Cedar pine (Pinus pumila) tree forms in the north of transbaikalian edge. Mezhdunarodnyy zhurnal nauchnykh i prikladnykh issledovaniy International Journal of Applied and Fundamental Research. 2014;8:9-13. In Russian

40. Gribkov PF. Kedrovyy stlanik drevovidnoy formy na Kamchatke [Tree-like form of Siberian dwarf pine in Kamchatka]. Voprosy geografii Kamchatki. 1964;2:114-115. In Russian

Received 09 February 2017; Revised 20 April 2017; Accepted 03 May 2017; Published 15 June 2017

\section{Author info:}

Vasilyeva Galina V, Cand. Sci. (Biol.), Researcher, Laboratory of Dendroecology, Institute of Monitoring of Climatic and Ecological Systems, Siberian Branch of the Russian Academy of Sciences, 10/3 Akademichesky Ave., Tomsk 634055, Russian Federation.

E-mail: galina_biology@mail.ru 